\title{
ROBUST CONTROL OF A WIND DRIVEN INDUCTION GENERATOR CONNECTED TO THE UTILITY GRID
}

\author{
A. A. Hassan ; Yehia S. Mohamed ; A. M. Kassem \\ Faculty of Engineering, Electrical Engineering Department, El-Minia \\ University, Minia, Egypt
}

\section{Ali M. Yousef}

Faculty of Engineering, Electrical Engineering Department., Assiut

University, Assiut, Egypt

(Received September 8, 2005 Accepted October 29, 2005)

This paper investigates the use of the linear quadratic Gaussian controller to control the voltage and frequency of a wind energy conversion scheme. This scheme cosists of a wind turbine and induction generator connected to the utility grid via $A C-D C-A C$ asynchronous link. The control objective aims to regulate the rectifier output voltage and track the maximum available wind power. This is accomplished via controlling the firing angles of the rectifier and the inverter. The complete nonlinear dynamic model of the system has been described and linearized arround an operating point. The standard Kalman filter technique has been employed to estimate the full states of the system. The computational burden has been minimized to a great extent by computing the optimal state feedback gains and the Kalman state space model off-line. The proposed controller has the advantages of robustness, fast response and good performance.

The wind energy scheme with the proposed controller has been tested through a step change in wind speed. Simulation results show that accurate tracking performance of the proposed wind energy scheme has been achieved. Moreover, this scheme is robust against the parameters variation and eliminates the influence of modeling and measurement noises.

KEYWORDS: wind turbine, induction generator, Kalman filter - robust control

\section{NOMENCLATURE}

$$
\begin{array}{ll}
v_{d s}, v_{q s} & d-q \text { stator voltages, } \\
i_{d s}, i_{q s} & d-q \text { stator currents, } \\
i_{d r}, i_{q r} & d-q \text { rotor currents, }
\end{array}
$$




$\begin{array}{ll}R_{s}, R_{r} & \text { stator and rotor resistances per phase } \\ L_{s}, L_{r}, L_{m} & \text { stator, rotor and magnetizing inductances } \\ C_{0} & \text { self excitation capacitance per phase } \\ \omega_{s} & \text { Angular stator frequency of the induction generator } \\ \omega_{m} & \text { Angular rotor speed (electrical rads/s) of the induction } \\ J & \text { generator } \\ f & \text { moment of inertia } \\ p & \text { friction coefficient } \\ L_{D C} & \text { differential operator d/dt } \\ R_{D C} & \text { DC-link inductance } \\ \alpha_{R}, \alpha_{I} & \text { DC-link resistance } \\ v_{d c o n}, v_{q c o n} & \text { firing angles of the converter and inverter. } \\ i_{d c o n}, i_{q c o n} & \text { d-q input voltage of the converter. } \\ I_{D C} & \text { DC-link current. } \\ v_{\text {inv }} & \text { inverter output voltage } \\ P & \text { number of pole pairs }\end{array}$

\section{INTRODUCTION}

In recent years, there has been growing interest towards the utilization of wind energy in the generation of electric power. In most cases, induction generators are used due to their high reliability, low price, ruggedness, and reduced maintenance costs. One of the simplest methods of running a wind generation system is to use an induction generator connected directly to the utility grid. This is very common method of operation which forces the machine to run at constant frequency and therefore at nearly constant speed. In such systems, it is difficult to control the flow of reactive power and so the grid voltage level [1]. Therefore it is desirable to operate a wind turbine at variable wind speeds. In this case, the turbine is able to operate at its maximum power producing point for a given wind speed.

Various control strategies have been proposed for regulating grid voltage and / or achieving optimal out of the turbine. In some schemes, the wind turbine drives an induction generator connected to grid through a static converter [2-3]. Other control schemes use search methods that vary the speed until optimal power is obtained [4-5]. However, these techniques have the difficulty of tracking the wind which will cause additional stress on the shaft.

Recently, advanced control tehniques, which were applied successfully on the machine drives, have been proposed for regulating the wind power in a grid connected wind energy conversion scheme. They include variable structure control [6-7], direct 
power control using space vector modulation [8-9], fuzzy control [10], and vector control [11]. In these methods, the speed feedback may be necessary to avoid instability. Moreover, wind velocity information may be needed as well. Also, the key point of direct power schemes is a correct and fast estimation of the active and reactive power as well as fast PI controllers.

This paper presents the voltage and frequency control of a wind driven induction generator connected to the utility grid via an asynchronous AC-DC-AC link. The nonlinear dynamic model of the wind energy system has been described and linearized around an operating point. The Linear Quadretic Gaussian ( LQG ) controller has been employed to regulate the DC voltage at the rectifier output and to track maximum available wind power. This is achieved by controlling the firing angles of the converter and inverter respectively. The structure of the LQG consists of a Kalman filter estimator and optimal state feedback gains. The Kalman estimator uses the measured $\mathrm{d}-\mathrm{q}$ stator current components in order to estimate all the system states including the d-q rotor current components, generator angular speed, d-axis generated voltage, DC link current, rectifier and inverter firing angles. These states are multiplied by the corresponding optimal gains and summed to produce the necessary control signals.

Computer simulations have been carried out in order to validate the effectiveness of the proposed scheme. The results proved that the proposed controller can give better overall performance regarding to high estimation accuracy, quick recover from wind speed disturbance in addition to good tracking ability.

\section{SYSTEM DESCRIPTION}

Figure 1 shows a wind energy system connected to the utility grid via an asynchronous AC-DC-AC link. It consists of a vertical axis wind turbine, driving a self excited induction generator. The asynchronous link consists of a six pulse line commutated converter, a smoothing reactor, and a six pulse line commutated inverter. This system essentially converts the variable voltage variable frequency voltage at the induction generator terminals to constant voltage constant frequency at the grid terminals. The DC link decouples the induction generator and the utility systems such that each system operates at its own frequency. This enables the induction generator to operate over a wide speed range. The flow of power across the DC link can be controlled by adjusting the firing angles of the controlled rectifier and the inverter.

\section{SYSTEM DYNAMIC MODEL}

The dynamic models of the different parts of the system can be described as follows :

\subsection{Wind Turbine Dynamic Model}

The wind turbine is characterized by nondimensional curves of the power coefficient $C_{p}$ as a function of both the tip speed ratio, $\lambda$ and the blade pitch angle, $\beta$. In order to fully utilize the available wind energy, the value of $\lambda$ should be maintained at its optimum value. Hence, the power coefficient corresponding to that value will become maximum also. 
The tip speed ratio $\lambda$ can be defined as the ratio of the angular rotor speed of the wind turbine to the linear wind speed at the tip of the blades. It can be expressed as follows:

$$
\lambda=\omega_{t} R / V_{w}
$$

Where $R$ is the wind turbine rotor radius, $V_{w}$ is the wind speed and $\omega_{t}$ is the mechanical angular rotor speed of the wind turbine.

The output power of the wind turbine, can be calculated from the following equation [10]:

$$
P_{m}=0.5 \rho A C_{p} V_{w}^{3}
$$

Where $\rho$ is the air density, and $A$ is the swept area by the blades.

Also, the torque available from the wind turbine can be expressed as :

$$
T_{m}=0.5 \rho A R C_{p} V_{w}^{2} / \lambda
$$

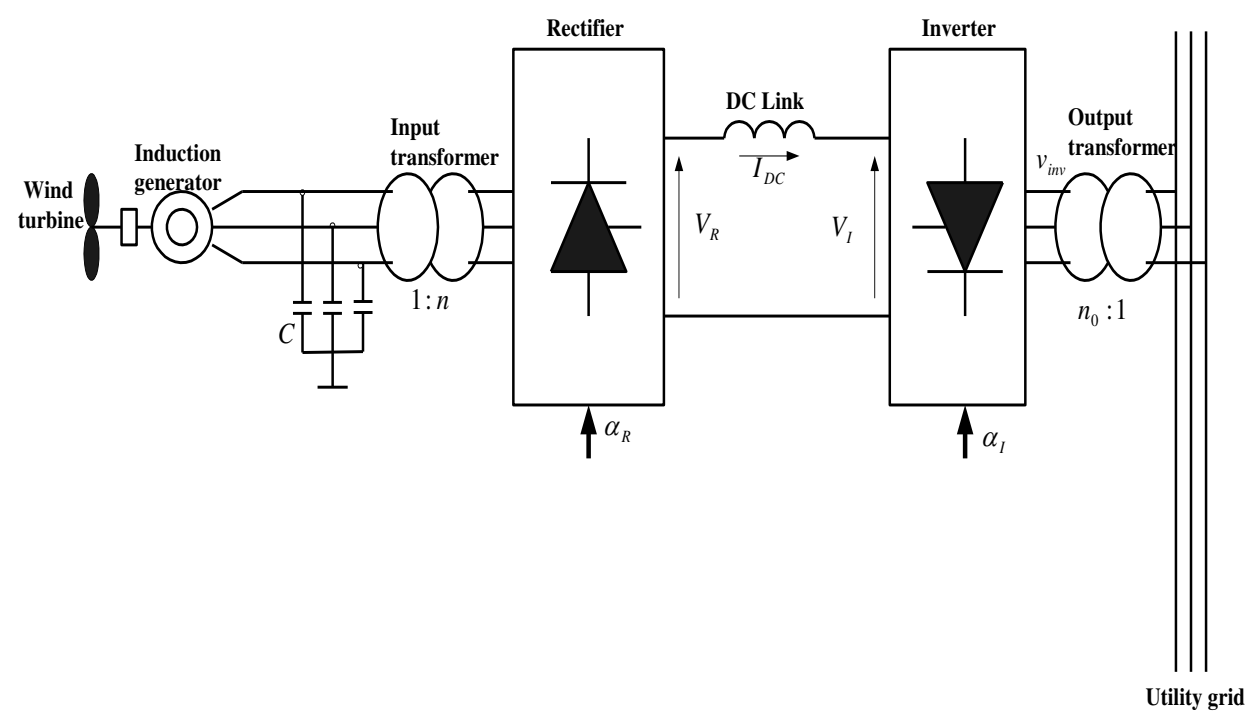

Fig. 1: Schematic diagram of the proposed wind energy system.

\subsection{Induction Generator Dynamic Model}

The dynamic behavior of the induction generator in the $\mathrm{d}-\mathrm{q}$ axis synchronously rotating reference frame is given by [12] :

$$
\begin{aligned}
& p i_{q s}=-R_{s} A_{1} i_{q s}-\left(\omega_{s}+A_{2} \omega_{m} L_{m}\right) i_{d s}+R_{r} A_{2} i_{q r}-A_{1} \omega_{m} L_{r} i_{d r} \\
& p i_{d s}=\left(\omega_{s}+A_{2} \omega_{m} L_{m}\right) i_{q s}-R_{s} A_{1} i_{d s}+R_{r} A_{2} i_{d r}+A_{1} \omega_{m} L_{m} i_{q r}-A_{1} v_{d s}
\end{aligned}
$$




$$
\begin{gathered}
p i_{q r}=R_{s} A_{2} i_{q s}+A_{2} \omega_{m} L_{s} i_{d s}-A_{3} i_{q r}+\left(-\omega_{s}+A_{1} \omega_{m} L_{s}\right) i_{d r} \\
p i_{d r}=-A_{2} \omega_{m} L_{s} i_{q s}+R_{s} A_{2} i_{d s}+\left(\omega_{s}-A_{1} \omega_{m} L_{s}\right) i_{q r}-A_{3} i_{d r}+A_{2} v_{d s}
\end{gathered}
$$

Where $v_{q s}=0$, due to the choice of axis alignment, and

$$
K_{1}=L_{r} /\left(L_{s} L_{r}-L_{m}^{2}\right), \quad K_{2}=L_{m} /\left(L_{s} L_{r}-L_{m}^{2}\right), \quad \text { and } \quad K_{3}=R_{r}\left(1+A_{2} L_{m}\right) / L_{r}
$$

The rotor speed $\omega_{m}$ is governed by the following differential equation:

$$
T_{m}+T_{e}=(J p+f) \omega_{m} / P
$$

Where $T_{m}$ is the input torque from the prim-mover, and $T_{e}$ is the electromagnetic torque representing the load on the induction generator $\left(T_{e}\right.$ is negative for generator action ) which is given by :

$$
T_{e}=1.5 P L_{m}\left(i_{q s} i_{d r}-i_{d s} i_{q r}\right)
$$

Equations (8) and (9) are combined as

$$
p \omega_{m}=\left(-f \omega_{m}+P T_{m}+1.5 P^{2} L_{m}\left(i_{q s} i_{d r}-i_{d s} i_{q r}\right)\right) / J
$$

\subsection{Asynchronous Dc Link Model}

The asynchronous DC link ( used to interface the wind energy system to the utility ) consists of a six pulse line commutated converter, a smoothing reactor, and a six pulse line commutated inverter. An isolating transformer of turns ratio $1: n$ interconnects the induction generator to the converter. Neglecting the resistance and leakage reactance of the isolating transformer, the various ac quantities on the primary and secondary sides can be related by:

$$
v_{d c o n}=n v_{d s}, \quad v_{q c o n}=n v_{q s}, \quad i_{q c o n}=i_{q l} / n, \quad i_{d c o n}=i_{d l} / n
$$

Assuming the converter is lossless, the instantaneous power balance equation ( $v_{q c o n}=0$, due to the choice of axis alignment ) :

$$
\frac{3}{2} v_{d c o n} i_{d c o n}=V_{R} I_{D C}
$$

Where $V_{R}$ is the DC voltage at the converter output terminals which can be written as :

$$
V_{R}=\frac{3 \sqrt{3}}{\pi} n v_{d s} \cos \alpha_{R}
$$

The ac and dc currents of the converter are related by :

$$
i_{c o n}=\sqrt{\left(i_{q c o n}^{2}+i_{d c o n}^{2}\right)}=\frac{2 \sqrt{3}}{\pi} I_{D C}
$$


Neglecting the commutation overlap, the d-q converter currents can be deduced using equations (12-14) as :

$$
\begin{array}{r}
i_{d c o n}=i_{c o n} \cos \alpha_{R}=\frac{2 \sqrt{3}}{\pi} I_{D C} \cos \alpha_{R} \\
i_{q c o n}=-i_{c o n} \sin \alpha_{R}=-\frac{2 \sqrt{3}}{\pi} I_{D C} \sin \alpha_{R}
\end{array}
$$

Referring to Fig. (1), the dynamics introduced by the DC link is given by:

$$
L_{D C} p I_{D C}+R_{D C} I_{D C}=V_{R}-V_{I}
$$

Where $V_{I}$ is the DC voltage at the inverter input terminals which can be expressed as :

$$
V_{I}=-\frac{3 \sqrt{3}}{\pi} v_{i n v} \cos \alpha_{I}+\frac{3 x_{c i}}{\pi} I_{D C}
$$

Combining equations (12), (17), and (18) the following equation can be obtained :

$$
p I_{D C}=\left(-R_{D C} I_{D C}+\frac{3 \sqrt{3}}{\pi} n v_{d s} \cos \alpha_{R}+\frac{3 \sqrt{3}}{\pi} v_{i n v} \cos \alpha_{I}-\frac{3 x_{c i}}{\pi} I_{D C}\right) / L_{D C}
$$

\subsection{Self Excitation Capacitor Model}

Referring to the d-q equivalent circuit of the self excitation capacitor shown in Fig. 2, the following differential equations can be written as:

$$
\begin{aligned}
& p v_{q s}=\frac{i_{q c}}{C_{0}}-\omega_{s} v_{d s} \\
& p v_{d s}=\frac{i_{d c}}{C_{0}}+\omega_{s} v_{q s}
\end{aligned}
$$

Since, $v_{q s}=0$, due to the choice of axis alignment, equations (18-19) can be rewritten as:

$$
\begin{gathered}
\omega_{s}=\frac{i_{q c}}{C_{0} v_{d s}} \\
p v_{d s}=\frac{i_{d c}}{C_{0}}
\end{gathered}
$$

Referring to Fig. (2), the values of $i_{q c}$ and $i_{d c}$ can be written as:

$$
i_{q c}=i_{q s}-i_{q l} \quad, \quad i_{d c}=i_{d s}-i_{d l}
$$

Equations (11, 14 and 15) are combined with equation (22) as : 

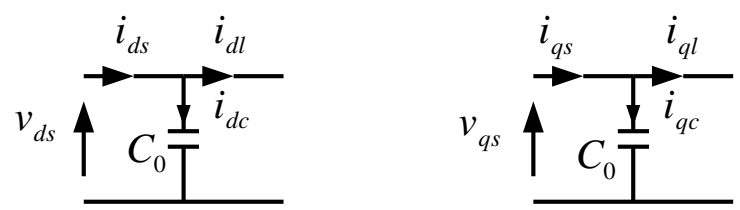

Fig. 2 : d-q equivalent circuit of the self excitation capacitor.

$$
i_{q c}=i_{q s}+\frac{2 \sqrt{3}}{\pi} n I_{D C} \sin \alpha_{R} \quad, \quad i_{d c}=i_{d s}-\frac{2 \sqrt{3}}{\pi} n I_{D C} \cos \alpha_{R}
$$

Substituting the values of $i_{q c}$ and $i_{d c}$ from equation (25) into equations (22) and (23) would give :

$$
\begin{gathered}
\omega_{s}=\frac{i_{q s}+\frac{2 \sqrt{3}}{\pi} n I_{D C} \sin \alpha_{R}}{C_{0} v_{d s}} \\
p v_{d s}=\frac{i_{d s}-\frac{2 \sqrt{3}}{\pi} n I_{D C} \cos \alpha_{R}}{C_{0}}
\end{gathered}
$$

Equation (26) can be used to determine the electrical frequency of the voltage generated by the induction generator.

\subsection{Voltage Regulator Model}

The DC voltage at the output of the converter terminals can be regulated by controlling the firing angle $\alpha_{R}$ as described in the following differential equation :

$$
p \alpha_{R}=V_{r e f}-V_{R}=V_{r e f}-\frac{3 \sqrt{3}}{\pi} n v_{d s} \cos \alpha_{R}
$$

where $V_{\text {ref }}$ is the reference voltage of the converter output.

\subsection{Power Regulator Model}

The power output of the converter ( power delivered to the asynchronous ACDC-AC link by the wind energy system ) can be adjusted via controlling the inverter firing angle $\alpha_{I}$ according to the following differential equation :

$$
p \alpha_{I}=P_{r e f}-P=P_{r e f}-\left(\frac{3 \sqrt{3}}{\pi} n v_{d s} \cos \alpha_{R}\right) I_{D C}
$$

where $P_{r e f}$ is the reference power at the output of the converter. 


\subsection{Complete System Model}

The subsystem models can be interfaced to form the unified nonlinear model after substituting $\omega_{s}$ from equation (26). The complete system model can be described as :

$$
\begin{aligned}
& p i_{q s}=-R_{s} K_{1} i_{q s}-\left(\frac{i_{q s}+\frac{2 \sqrt{3}}{\pi} n I_{D C} \sin \alpha_{R}}{C_{0} v_{d s}}+K_{2} \omega_{m} L_{m}\right) i_{d s}+R_{r} K_{2} i_{q r}-K_{1} \omega_{m} L_{r} i_{d r} \\
& p i_{d s}=\left(\frac{i_{q s}+\frac{2 \sqrt{3}}{\pi} n I_{D C} \sin \alpha_{R}}{C_{0} v_{d s}}+K_{2} \omega_{m} L_{m}\right) i_{q s}-R_{s} K_{1} i_{d s}+R_{r} K_{2} i_{d r}+K_{1} \omega_{m} L_{m} i_{q r}-K_{1} v_{d s} \\
& p i_{q r}=R_{s} K_{2} i_{q s}+K_{2} \omega_{m} L_{s} i_{d s}-K_{3} i_{q r}+\left(-\frac{i_{q s}+\frac{2 \sqrt{3}}{\pi} n I_{D C} \sin \alpha_{R}}{C_{0} v_{d s}}+K_{1} \omega_{m} L_{s}\right) i_{d r} \\
& \left(\frac{i_{q s}+\frac{2 \sqrt{3}}{\pi} n I_{D C} \sin \alpha_{R}}{C_{0} v_{d s}}-K_{1} \omega_{m} L_{s}\right) i_{q r}-K_{3} i_{d r}+K_{2} v_{d s} \\
& p \omega_{m}=\left(-f \omega_{m}+P T_{m}+1.5 P^{2} L_{m}\left(i_{q s} i_{d r}-i_{d s} i_{q r}\right)\right) / J \\
& p v_{d s}=\frac{i_{d s}-\frac{2 \sqrt{3}}{\pi} n I_{D C} \cos \alpha_{R}}{C_{0}} \\
& p I_{D C}=\left(-R_{D C} I_{D C}+\frac{3 \sqrt{3}}{\pi} n v_{d s} \cos \alpha_{R}+\frac{3 \sqrt{3}}{\pi} v_{i n v} \cos \alpha_{I}-\frac{3 x_{c i}}{\pi} I_{D C}\right) / L_{D C} \\
& p \alpha_{R}=V_{r e f}-V_{R}=V_{r e f}-\frac{3 \sqrt{3}}{\pi} n v_{d s} \cos \alpha_{R} \\
& p \alpha_{I}=P_{r e f}-P=P_{r e f}-\left(\frac{3 \sqrt{3}}{\pi} n v_{d s} \cos \alpha_{R}\right) I_{D C}
\end{aligned}
$$

\section{CONTROL STRATEGY}

In this paper, the LQG controller has been proposed to control a wind energy system connected to the utility grid via an asynchronous AC-DC-AC link. The LQG is a modern state space technique for designing optimal dynamic regulators. It has the following advantages :

1) It enables to trade off regulation performance and control effort.

2) It takes into account the process disturbance and measurement noise. 
The main control objective is to regulate the DC voltage at the output of the converter and to track and extract maximum available wind power. This is achieved by controlling the firing angles of the converter and inverter respectively.

The LQG controller proposed for controlling the wind energy conversion scheme is based on the state space linear model of the system. Therefore, the nonlinear model of the complete system is linearized arround an operating point. The linearized model has the following state matrix form :

$$
p x=A x+B u, \quad y=C x
$$

where $x=\left[\begin{array}{lllllllll}\Delta i_{q s} & \Delta i_{d s} & \Delta i_{q r} & \Delta i_{d r} & \Delta \omega_{s} & \Delta v_{d s} & \Delta I_{D C} & \Delta \alpha_{R} & \Delta \alpha_{I}\end{array}\right]^{T}$,

$$
u=\left[\begin{array}{ll}
\Delta V_{r e f} & \Delta P_{r e f}
\end{array}\right]^{T},
$$

$\mathrm{A}=\left[a_{i j}\right]$ is a $9 \times 9$ matrix where the elements $a_{i j}$ are written in appendix (A) .

The LQG controller consists of an optimal state feedback gain " $k$ " and a Kalman state estimator. The optimal feedback gain is calculated such that the feedback control law $u=-k x$ minimizes the performance index :

$$
H=\int_{0}^{\infty}\left(x^{T} Q x+u^{T} R u\right) d t
$$

where $Q$ and $R$ are positive definite or semi definite Hermittian or real symmetric matrices. The optimal state feedback $u=-k x$ is not implementable without full state measurement. In our case, the states are chosen to be the perturbations in stator and rotor current components, speed, stator voltage, DC current, rectifier and inverter firing angles. The stator current components are chosen to be the only output measured signals. The Kalman filter estimator is used to drive the state estimation :

$\hat{x}=\left[\begin{array}{lllllllll}\Delta \hat{i}_{q s} & \Delta \hat{i}_{d s} & \Delta \hat{i}_{q r} & \Delta \hat{i}_{d r} & \Delta \hat{\omega}_{m} & \Delta \hat{v}_{d s} & \Delta \hat{I}_{D C} & \Delta \hat{\alpha}_{R} & \Delta \hat{\alpha}_{I}\end{array}\right]^{T}$,

such that $u=-k \hat{x}$ remains optimal for the output feedback problem. The state estimation is generated from :

$$
\hat{p x}=(A-B k-L C) \hat{x}+L y
$$

Where $\mathrm{L}$ is the Kalman gain which is determined by knowing the system noise and measurement covariances $Q_{n}$ and $R_{n}$. However, the accuracy of the filter's performance depends heavily upon the accuracy of these covariances. On the other hand the matrices $A$ and $B$ containing the motor parameters are not required to be very accurate due to the inherent feedback nature of the system. Fortunately, the Kalman filter performs best for linear systems. The optimal state feedback gains and the Kalman state space model have been calculated off-line which results in great 
saving in computational burden. On this basis, the implementation of the proposed controller becomes easier and the hardware will be reduced to minimum.

\section{SYSTEM CONFIGURATION}

The block diagram of the wind energy conversion system with the proposed LQG controller is shown in Fig. 3.

The LQG controller contains the Kalman state estimator in addition to optimal state feedback gains. The Kalman estimator uses the measured d-q stator current components in order to estimate all the states including the $\mathrm{d}-\mathrm{q}$ rotor current components, generator speed, d-axis generated voltage, DC link current, rectifier firing angle, position and load torque. These states are multiplied by the corresponding optimal gains and summed to produce the control signals necessary to regulate the DC voltage at the output of the converter and to track and extract maximum available wind power.

The entire system has been simulated on the digital computer using the Matlab / Simulink / Powerlib software package. The specifications of the system used in the simulation procedure are listed in appendix (B)[12].

The noise and measurement covariances are set as :

$$
Q_{n}=\operatorname{diag}(10,10) \quad, R_{n}=\operatorname{diag}(1,1)
$$

Also, the values of $Q$ and $R$ matrices which are necessary to calculate the optimal feedback gains are set as: $Q=\operatorname{diag}\left(\begin{array}{lllll}4001 & 1 & 1 & 1 & 1000\end{array}\right), R=\operatorname{diag}(0.00030 .0003)$.

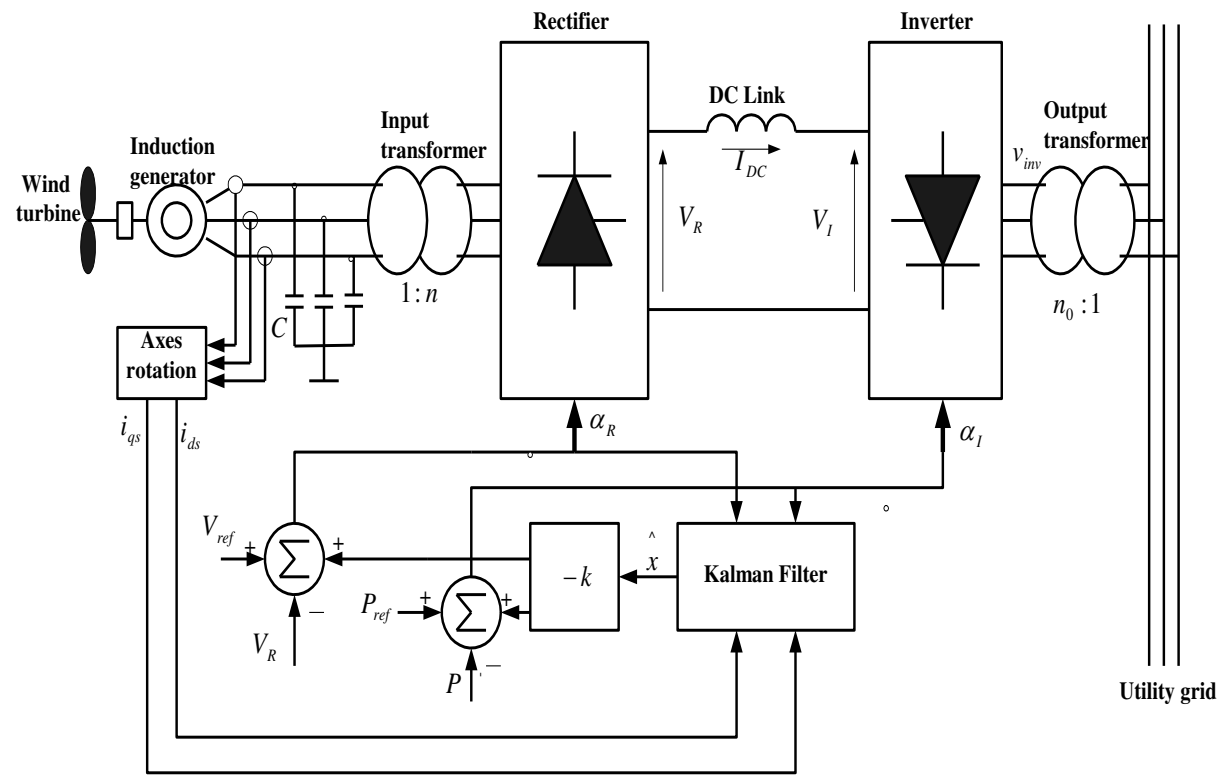

Fig. 3: Block diagram of the wind energy conversion system with the proposed LQG controller. 


\section{RESULTS}

Computer simulations have been carried out in order to validate the effectiveness of the proposed scheme. The performance of the proposed system has been tested with a step change in wind speed. Figure $\mathbf{4}$ shows the dynamic responses of the induction generator electrical rotor speed, input torque, rectifier output voltage, DC link current, rectifier output power, and the firing angles for both rectifier and inverter. It has been noticed in the figure that as the wind velocity increases from 6.4 $\mathrm{m} / \mathrm{sec}$. to $6.5 \mathrm{~m} / \mathrm{sec}$., the shaft torque developed by the wind turbine increases also, and the induction generator will be accelerated. As the rotor speed increases, the induction generator terminal voltage tends to increase. Hence, the LQG controller will increase the firing angle of the rectifier in order to keep the DC link voltage at the specified level.

On the other hand, as the wind velocity increases, the power output of the wind turbine will increase because it is proportional to the cube of the wind velocity. Hence to track and extract maximum available wind power, the inverter power output should be correspondingly increased. Therefore, the LQG controller increases the inverter firing angle in order to track the change of the wind power.
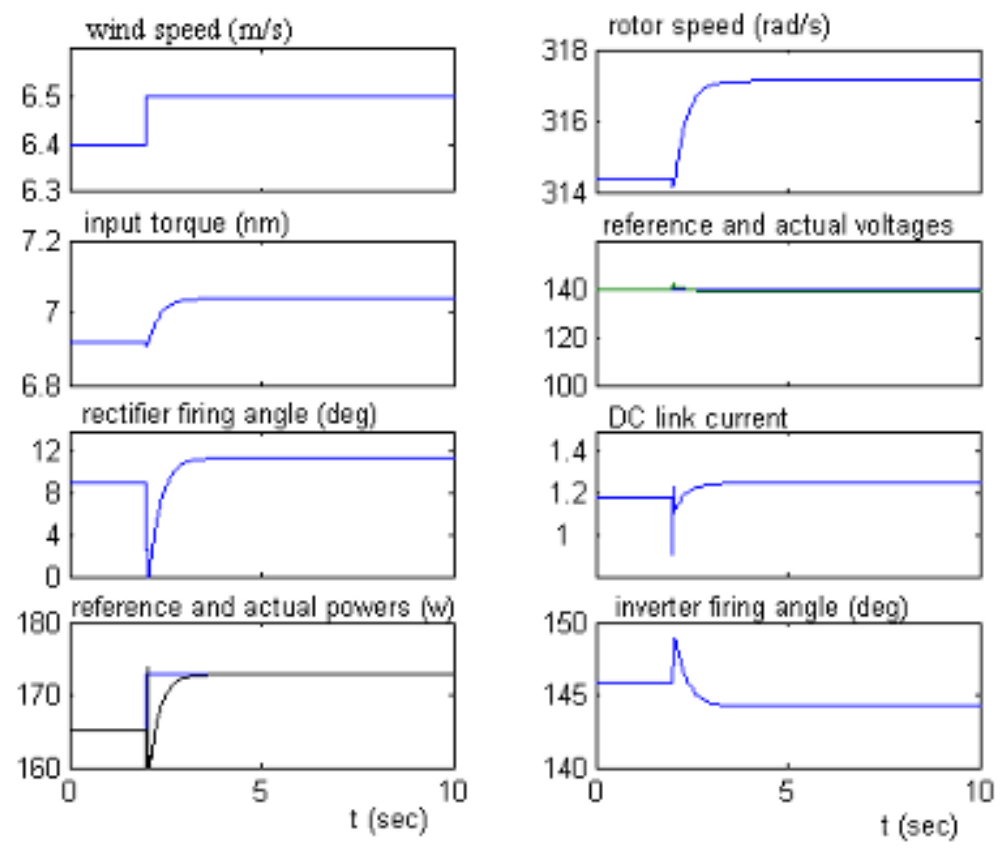

Fig. 4: Dynamic responses of the wind energy conversion system with the proposed LQG controller

\section{CONCLUSIONS}

This paper presents the application of a high dynamic optimal regulator to control a wind driven induction generator connected to the utility grid via AC-DC-AC asynchronous link. Thus, the LQG controller has been used to regulate the rectifier 
output voltage and track the maximum available wind power. The complete nonlinear dynamic model of the system has been described and linearized around an operating point. The standard Kalman filter technique has been employed to estimate the full states of the system. The stator current components are the only measured signals. The computational burden has been minimized to a great extent by computing the optimal state feedback gains and the Kalman state space model off-line. The proposed controller has the advantages of robustness, easy implementation and good performance in the face of uncertainties.

Computer simulations have been carried out in order to evaluate the effectiveness of the proposed controller. The results prove that accurate tracking performance of the propsed wind energy scheme has been achieved at step change in wind speed. Moreover, this scheme is robust against the parameters variation and eliminates the influence of modeling and measurement noises.

\section{REFERENCES}

[1] G. Saccomando, J. Svensson and A. Sannino, " Improving voltage disturbance rejection for variable-speed wind turbines", IEEE Trans. On Energy Conversion, Vol. 17, No. 3, September, 2002, pp 422-428.

[2] A. Miller, E. Muljadi and D. S. Zinger, " A variable speed wind turbine power control", IEEE Trans. On Energy Conversion, Vol. 12, No. 2, June, 1997, pp 181-186.

[3] A. Abdin and X. Wilson, " Control design and dynamic performance analysis of a wind turbine-induction generator unit", IEEE Trans. On Energy Conversion, Vol. 15, No. 1, March, 2000, pp 91-96.

[4] R. Spee, S. Bhowmik and J. H. R Enslin, " Adaptive control strategies for variable-speed doubly-fed wind power generation systems", IAS Annual meeting, October, 1995, pp 545-552.

[5] M. G. Simoes, B. K. Bose and R. J. Spiegel, "Fuzzy logic based intelligent control of a variable speed cage machine wind generation system", PFSC, 1995, pp 389-395.

[6] H. De Battista and R. J. Mantz "Dynamical variable stracture controller for power regulation of wind energy conversion systems", IEEE Trans. On Energy Conversion, Vol. 19, No. 4, December 2004, pp 756-763.

[7] H. DE Battista, R. Mantz and C. Christiansen, "Dynamical sliding mode power control of wind driven induction generators", IEEE Trans. On Energy Conversion, Vol. 15, December 2000, pp 451-457.

[8] A. S. Neris, N. A. Vovos and G. B. Giannakopoulos, "A variable speed wind energy conversion scheme for connection to weak AC systems", IEEE Trans. On Energy Conversion, Vol. 14, no. 1, March 1999, pp 304-311.

[9] M. Malinowski and S. Bernet, "Simple control scheme of PWM converter connecting wind turbine with grid-simulation study", Nordic wind power conf., Chalimars of technology, March, 2004.

[10] M. Godoy, B. K. Bose and R. J. Spiegel, "design and performance evaluation of a fuzzy-logic-based variable-speed wind generation system", IEEE Trans. On Energy Conversion, Vol. 33, no. 4, July 1997, pp 956-964. 
[11] R. Cardenas and R. Pena, "Sensorless vector control of induction machines for variable-speed wind energy applications", IEEE Trans. On Energy Conversion, Vol. 19, no. 1, March 2004, pp 196-205.

[12] R. M. Hilloowala, " Control and interface of renewable energy systems", Ph.D. Thesis, The University of New Brunswick, Canada, 1992.

\section{Appendix A}

The elements $a_{i j}$ of the $9 \times 9$ matrix $\mathrm{A}$ are :

$$
\begin{aligned}
& a_{11}=-R_{s} K_{1}-\left(I_{d s 0} / C_{0} V_{d s 0}\right), \\
& a_{12}=-\left(I_{q s 0} / C_{0} V_{d s 0}\right)-\left(\frac{2 \sqrt{3} n I_{D C 0} \sin \alpha_{R 0}}{\pi C_{0} V_{d s 0}}\right)-K_{2} \omega_{m 0} L_{m}, \\
& a_{13}=-a_{24}=-R_{r} K_{2}, \quad a_{14}=-K_{1} \omega_{m 0} L_{r}, a_{15}=-K_{2} L_{m} I_{d s 0}-K_{1} L_{r} I_{d r 0}, \\
& \left.a_{16}=\frac{I_{q s 0}+\frac{2 \sqrt{3}}{\pi} n I_{D C 0} \sin \alpha_{R 0}}{C_{0}\left(V_{d s 0}\right)^{2}}\right)-K_{2} \omega_{m 0} L_{m}, a_{17}=-\left(\frac{2 \sqrt{3} n I_{d s 0} \sin \alpha_{R 0}}{\pi C_{0} V_{d s 0}}\right), \\
& a_{18}=-\left(\frac{2 \sqrt{3} n I_{d c 0} \cos \alpha_{R 0}}{\pi C_{0} V_{d s 0}}\right), \\
& a_{21}=\left(2 I_{q s 0} / C_{0} V_{d s 0}\right)+\left(\frac{2 \sqrt{3} n I_{D C 0} \sin \alpha_{R 0}}{\pi C_{0} V_{d s 0}}\right)+K_{2} \omega_{m 0} L_{m} \\
& a_{22}=-R_{s} K_{1}, \quad a_{23}=-K_{1} \omega_{m 0} L_{m} \quad, \quad a_{25}=K_{2} L_{m} I_{q s 0}+K_{1} L_{m} I_{q r 0}, \\
& a_{26}=\frac{-\left[\left(I_{q s 0}\right)^{2}+\frac{2 \sqrt{3}}{\pi} n I_{q s 0} I_{D C 0} \sin \alpha_{R 0}\right]}{C_{0}\left(V_{d s 0}\right)^{2}}-K_{1} \quad, \quad a_{27}=\frac{2 \sqrt{3} n I_{q s 0} \sin \alpha_{R 0}}{\pi C_{0} V_{d s 0}}, \\
& a_{28}=\frac{2 \sqrt{3} n I_{D C 0} I_{q s 0} \cos \alpha_{R 0}}{\pi C_{0} V_{d s 0}}, a_{31}=a_{42}=R_{s} K_{2} \quad, \quad a_{32}=K_{2} \omega_{m 0} L_{s}, \\
& a_{33}=a_{44}=-R_{r}\left(1+K_{2} L_{m}\right) / L_{r}, \\
& a_{34}=-a_{43}=-\frac{I_{q s 0}+\frac{2 \sqrt{3}}{\pi} n I_{D C 0} \sin \alpha_{R 0}}{C_{0} V_{d s 0}}+K_{1} \omega_{m 0} L_{s},
\end{aligned}
$$




$$
\begin{aligned}
& a_{35}=K_{2} L_{s} I_{d s 0}+K_{1} L_{s} I_{d r 0} \quad, \quad a_{36}=\left(\frac{I_{q s 0}+\frac{2 \sqrt{3}}{\pi} n I_{D C 0} \sin \alpha_{R 0}}{C_{0}\left(V_{d s 0}\right)^{2}}\right) I_{d r 0}, \\
& a_{37}=-\frac{2 \sqrt{3} n I_{d r 0} \sin \alpha_{R 0}}{\pi C_{0} V_{d s 0}}, a_{38}=\frac{-2 \sqrt{3} n I_{D C 0} I_{d r 0} \cos \alpha_{R 0}}{\pi C_{0} V_{d s 0}}, \\
& a_{41}=\left(I_{q r 0} / C_{0} V_{d s 0}\right)-K_{2} \omega_{m 0} L_{s}, \quad a_{45}=-K_{2} L_{s} I_{q s 0}+K_{1} L_{s} I_{q r 0} \\
& a_{46}=-\left(\frac{I_{q s 0}+\frac{2 \sqrt{3}}{\pi} n I_{D C 0} \sin \alpha_{R 0}}{C_{0}\left(V_{d s 0}\right)^{2}}\right) I_{q r 0}+K_{2}, \quad a_{47}=\frac{2 \sqrt{3} n I_{q r 0} \sin \alpha_{R 0}}{\pi C_{0} V_{d s 0}}, \\
& a_{48}=\frac{2 \sqrt{3} n I_{D C 0} I_{q r 0} \cos \alpha_{R 0}}{\pi C_{0} V_{d s 0}}, a_{51}=3 P^{2} L_{m} I_{d r 0} / 2 J, a_{52}=-3 P^{2} L_{m} I_{q r 0} / 2 J \text {, } \\
& a_{53}=-3 P^{2} L_{m} I_{d s 0} / 2 J, a_{54}=3 P^{2} L_{m} I_{q s 0} / 2 J, a_{55}=-f / J, a_{62}=\frac{1}{C_{0}} \\
& a_{67}=\frac{-2 \sqrt{3} n \cos \alpha_{R 0}}{\pi C_{0}}, \quad a_{68}=\frac{2 \sqrt{3} n I_{D C} \sin \alpha_{R 0}}{\pi C_{0}}, a_{76}=\frac{3 \sqrt{3}}{L_{D C} \pi} n \cos \alpha_{R}, \\
& a_{77}=\left(-R_{D C}-\frac{3 x_{c i}}{\pi}\right) / L_{D C}, \quad a_{78}=\left(-\frac{3 \sqrt{3}}{\pi} n V_{d s 0} \sin \alpha_{R 0}\right) / L_{D C}, \\
& a_{79}=\left(-\frac{3 \sqrt{3}}{\pi} n V_{d s 0} \sin \alpha_{R 0}\right) / L_{D C}, \quad a_{86}=\left(-\frac{3 \sqrt{3}}{\pi} n \cos \alpha_{R 0}\right), \\
& a_{88}=\left(\frac{3 \sqrt{3}}{\pi} n V_{d s 0} \sin \alpha_{R 0}\right), \\
& a_{96}=\left(-\frac{3 \sqrt{3}}{\pi} n I_{D C 0} \cos \alpha_{R 0}\right), a_{97}=\left(-\frac{3 \sqrt{3}}{\pi} n V_{d s 0} \cos \alpha_{R 0}\right), \\
& a_{98}=\left(\frac{3 \sqrt{3}}{\pi} n V_{d s 0} I_{D C 0} \sin \alpha_{R 0}\right), \\
& a_{19}=a_{29}=a_{39}=a_{49}=a_{56}=a_{57}=a_{58}=a_{59}=a_{61}=a_{63}=a_{64}=a_{65}=a_{66}=a_{69}=0 \text {, } \\
& a_{71}=a_{72}=a_{73}=a_{74}=a_{75}=a_{81}=a_{82}=a_{83}=a_{84}=a_{85}=a_{87}=a_{89}=0 \text {, } \\
& a_{91}=a_{92}=a_{93}=a_{94}=a_{95}=a_{99}=0 \text {. }
\end{aligned}
$$




\section{Appendix B : System Parameters}

\section{Wind Turbine :}

Rating: $1 \mathrm{kw}, 450 \mathrm{rpm}$ (low speed side) at $V_{w}=12 \mathrm{~m} / \mathrm{s}$.

Size : Height $=4 \mathrm{~m}$, Equator radius $=1 \mathrm{~m}$, Swept area $=4 \mathrm{~m}^{2}, \rho=1.25 \mathrm{~kg} / \mathrm{m}^{2}$.

\section{Induction Machine :}

Rating: 3-phase, $2 \mathrm{kw}, 120 \mathrm{~V}, 10 \mathrm{~A}, 4$-pole , $1740 \mathrm{rpm}$.

Parameters : $R_{s}=0.62 \Omega, R_{r}=0.566 \Omega, L_{s}=L_{r}=0.058174$ H.,$L_{m}=0.054 \mathrm{H}$, $J=0.0622 \mathrm{~kg} . \mathrm{m}^{2}, \quad f=0.00366 \mathrm{~N} . \mathrm{m} . / \mathrm{rad} / \mathrm{s}$.

DC Link : $R_{D C}=1.7 \Omega, L_{D C}=0.15 \mathrm{H}$,

\section{Self Excitation Capacitor:}

Rating: $176 \mu f$ / phase, $350 \mathrm{~V}, 8 \mathrm{~A}$.

\section{التحكم المثين في مولا حثي يعمل بطاقة الرياح ومتصل بالثبكة العمومية فية}

في هذا البحث تم اقتر اح استخدام متحكم جادس التربيعي الخطي (LQG) للتحكم في

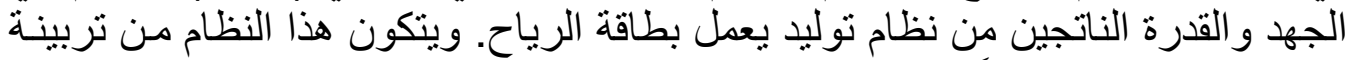

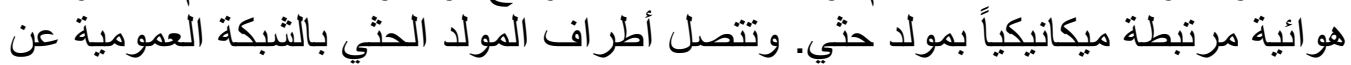

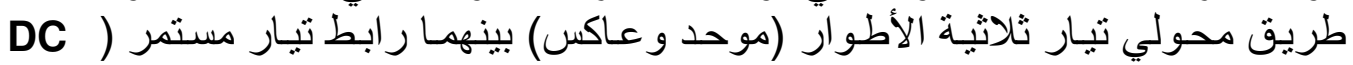

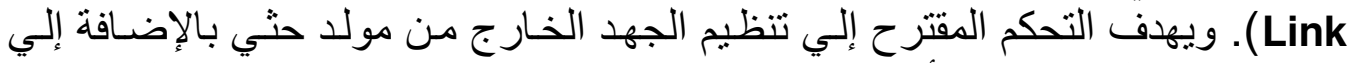

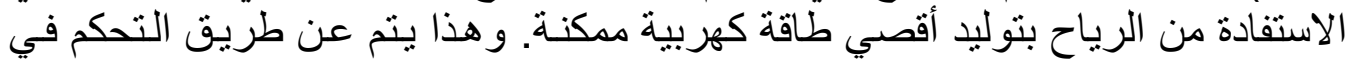
زوايا اشعال عناصر الثايرستور التي يحتويها كل من محولي التيار (الموحد و العاكس).

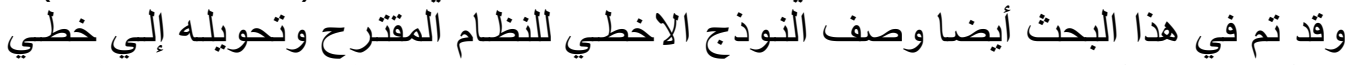

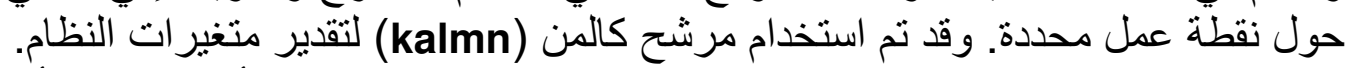

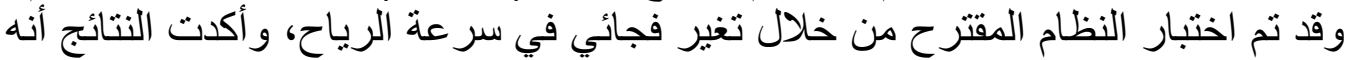

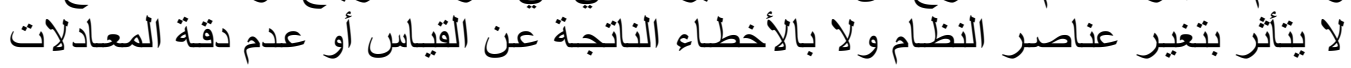
المستخدمة في وصف النظفر عنام. 